\title{
An Architecture for Developing Educational Recommender Systems
}

\author{
Maritza Bustos-López, Raquel Vásquez-Ramírez, Giner Alor-Hernández \\ Instituto Tecnológico de Orizaba, Division of Research and Postgraduate Studies, Veracruz, \\ Mexico \\ maritbustos@gmail.com,vz.rmz.raquel@gmail.com, galor@itorizaba.edu.mx
}

\begin{abstract}
The great amount of educational resources available on educational repositories enriches the learning process. However, it raises a new challenge: the need to provide support to the location of those resources that meet the needs, goals and preferences of each student. The location of useful educational resources to support the learning process is addressed by using recommender systems. Recommender systems are a tool to help student find information quickly and recommend new items of interest to the active student based on their preferences. In this paper, we propose a generic architecture for developing educational recommender systems independent of the type of recommendation generated. Also, we identify main features of an educational recommender system. These features are important components to achieve the objectives that have educational recommender systems in order to provide accurate information to students according to their preferences, user profile and learning objectives.
\end{abstract}

Keywords: Recommender systems, educational applications, collaborative filtering.

\section{Introduction}

Recommender systems are software tools and techniques providing suggestions for items to be of use to a user [1]. This kind of systems helps people to find items that the user is not aware, but that maybe of their interest. A recommender system assists in advertising tasks by automatically selecting the most appropriate items for each user according to his/her personal interests and preferences. Nowadays, many companies and Web sites implement recommender systems to study the preferences of users and adapt their products / information / services more appropriately to such interests in order to improve their results. In recent years, the interests in developing recommender systems has increased dramatically and have been proposed for different areas of knowledge as e-commerce, medicine, tourism, entertainment, education. In education, a recommender system imposes specific requirements and can take advantage of various types of knowledge in the referral process. For example, a recommender system can obtain the cognitive state of the student, which changes over time, and to carry out 
suggestions to change it. This would increase the level of customization in the long term. Another example, a recommender system can take advantage of a simple pedagogical rule as 'make difficult tasks easier ' or 'gradually reduce the amount of orientation'. Learning pathways and routes may represent sequences designed by professors from positive experiences in the classroom, or may correspond to the behavior of advanced students.

Recommender systems can be classified into five different categories depending on the technique employed to predict the utility of the items for the user, i.e., according to the recommendation technique [2]: (1) content-based recommender systems, (2) collaborative filtering recommender systems, (3) demographic recommender systems, (4) knowledge-based recommender systems, (5) hybrid recommender systems.

The implementation of techniques for the development of recommender systems is closely related to the type of information that will be used. A first source of information to keep in mind is the kind of elements that the system works. There are situations in which only an identifier of each element is known. For instance, in the case of the recommendation of educational resources, the title of the resource or resource content, the year in which the resource was developed, resource type, the author among other attributes are only known. This paper is organized as follows: Section 2 describes a review of previous related works. Section 3 presents the architectural design for educational recommender systems. The main features of Educational Recommender Systems are discussed in Section 4. Finally, future work and conclusions are presented in Section 5.

\section{State of the Art}

In the educational context, different recommender systems have been proposed in literature. A recommendation module of a programming tutoring system called Protus was developed in [3]. This module can be automatically adapted to the interests and knowledge levels of learners. Protus can recognize different patterns of learning style and learners' habits through testing the learning styles of learners and mining. Firstly, Protus processes the clusters based on different learning styles. Next, Protus analyzes the habits and the interests of the learners through mining the frequent sequences by the AprioriAll algorithm. Finally, Protus completes personalized recommendation of the learning content according to the ratings of these frequent sequences.

In [4] an educational collaborative filtering recommender agent was developed, with an integrated learning style finder. The agent produces two types of recommendations: suggestions and shortcuts for learning materials and learning tools, helping the learner to better navigate through educational resources.

A book recommendation system called PBRecS was developed in [5]. PBRecS is based on social interactions and personal interests to suggest books appealing to users. PBRecS relies on the friendships established on a social networking site, such as LibraryThing, to generate more personalized suggestions by including in the recommendations solely books that belong to a user's friends who share common interests with the user, in addition to apply word-correlation factors for partially matching book tags to disclose books similar in contents. 
A new material recommender system framework based on sequential pattern mining and multidimensional attribute-based collaborative filtering (CF) was proposed in [6]. In the sequential pattern based approach, modified Apriori and PrefixSpan algorithms were implemented to discover latent patterns in accessing materials and use them for recommendation. Leaner Preference Tree (LPT) is introduced to take into account multidimensional-attribute of materials, and learners' rating and model dynamic and multi-preference of learners in the multidimensional attribute-based CF approach.

An online personalized English learning recommender system capable of providing ESL students with reading lessons that suit their different interests and therefore increase the motivation to learn was developed in [7]. The recommender system, using content-based analysis, collaborative filtering, and data mining techniques, analyzes real students' reading data and generates recommender scores, based on which to help select appropriate lessons for respective students. Its performance having been tracked over a period of one year, this recommender system has proved to be very useful in heightening ESL learners' motivation and interest in reading.

In [8], a personalized auxiliary material recommendation system was proposed based on the degree of difficulty of the auxiliary materials, individual learning styles, and the specific course topics. The proposal is based on several studies in which the effects of using Facebook were investigated in various aspects of education and a learning platform was used for the exchange of auxiliary materials.

A new multi agent learning system, called ISABEL was proposed in [9]. ISABEL provides each student, which is using a specific device, with a device agent able to autonomously monitor the student's behavior when accessing e-learning Web sites. Each site is associated, in its turn, with a teacher agent. When a student visits an elearning site, the teacher agent collaborates with some tutor agents associated with the student, to provide him with useful recommendations.

An automatic personalization approach aiming to provide online automatic recommendations for active learners without requiring their explicit feedback was described in [10]. Recommended learning resources were computed based on the current learner's recent navigation history, as well as exploiting similarities and dissimilarities among learners' preferences and educational content. The proposed framework for building automatic recommendations in e-learning platforms is composed of two modules: (1) an off-line module which preprocesses data to build learner and content models, and (2) an online module which uses these models on-thefly to recognize the students' needs and goals, and predict a recommendation list.

A personalized recommender system that used web mining techniques for recommending a student which (next) links to visit within an adaptable educational hypermedia system was described in [11]. A specific mining tool and a recommender engine were integrated in the AHA! system in order to help the teacher to carry out the whole web mining process.

In [12], a system that allows lecturers to define their best teaching strategies to be used in the context of a specific class is presented. The context is defined by: the specific characteristics of the subject being treated, the specific objectives that are expected to be achieved in the classroom session, the profile of the students on the course, the dominant characteristics of the teacher, and the classroom environment for each session, among others. 
The system presented is the Recommendation System of Pedagogical Patterns (RSPP). A hybrid recommender system for learning materials based on their attributes to improve the accuracy and quality of recommendation was proposed in [13]. The system has two main modules: 1) explicit attribute-based recommender and 2) implicit attribute-based recommender. In the first module, weights of implicit or latent attributes of materials for learner are considered as chromosomes in a genetic algorithm then this algorithm optimizes the weights according to historical rating. Then, recommendation is generated by Nearest Neighborhood Algorithm (NNA) by using the optimized weight vectors implicit attributes that represent the opinions of learners. In the second module, preference matrix (PM) is introduced that can model the interests of learner based on explicit attributes of learning materials in a multidimensional information model. Then, a new similarity measure between PMs is introduced and recommendations are generated by NNA.

DELPHOS, a framework to assist users in the search for learning objects in repositories and which shows an example of application in engineering was proposed in [14]. LORs can be used in engineering not only for learning and training students, instructors and professionals but also for sharing knowledge about engineering problems and projects. The proposed approach is based on a weighted hybrid recommender that uses different filtering or recommendation criteria. The values of these weights can be assigned by the user him/herself or can be automatically calculated by DELPHOS in an adaptive and dynamic way.

In [15] a work-in-progress is presented with the aim of developing recommender system for personalization of activities in e-learning 2.0 environments. The main components of the proposed system are activity, student and group models, and recommender module. Activity model will be used for learning design representation and will include items that could be recommended to students: e-learning activities, possible collaborators, tools, and advices. To provide recommendations tailored to the student's and group's characteristics, an important component of the system will include student and group models. The recommender module, as third component of the system, will include original pedagogical rules together with the algorithms that adapt known recommendations techniques to the educational context.

Finally, E-learning resource recommendation was presented in [16], the project uses attribute of resources and learners and the sequential patterns of the learner's accessed resource in recommendation process. Learner Tree (LT) is introduced to take into account explicit multi-attribute of resources, time-variant multi-preference of learner and learners' rating matrix simultaneously. Implicit attributes are introduced and discovered using matrix factorization. BIDE algorithm also is used to discover sequential patterns of resource accessing for improving the recommendation quality.

In order to analyze more precisely the works described earlier, we present in table 1 a comparative analysis which summarizes relevant contributions of these related works.

These initiatives suffer from several drawbacks, such as: (a) Some works are based on the use of learning object as items to be recommended; (b) the multi-domain works use only one algorithm for the all domains; (c) these works are based only in the users rating for generating the recommendations. These deficiencies can be improved by: (a) a recommendation systems that implements a specified metric for each data type, utilizing the user and item information; (b) a system that automatically generates this 
kind of recommendation systems in an easy way providing a set of friendly user interfaces.

Table 1. Comparative analysis of proposals for educational recommender systems.

\begin{tabular}{|c|c|c|c|c|}
\hline Research Work & $\begin{array}{c}\text { Entity } \\
\text { type }\end{array}$ & Objective & Algorithm & $\begin{array}{c}\text { Recom } \\
\text { mender } \\
\text { System } \\
\text { Type } \\
\end{array}$ \\
\hline $\begin{array}{l}\text { A personalized } \\
\text { English learning } \\
\text { recommender } \\
\text { system [8] }\end{array}$ & Unknown & $\begin{array}{l}\text { Provide ESL students with reading } \\
\text { lessons that suit their different } \\
\text { interests and therefore increase the } \\
\text { motivation to learn. }\end{array}$ & $\begin{array}{l}\text { Clustering } \\
\text { Association rules } \\
\text { algorithm }\end{array}$ & Hybrid \\
\hline Protus [3] & $\begin{array}{l}\text { Learning } \\
\text { objects }\end{array}$ & $\begin{array}{l}\text { Estimate automatic } \\
\text { recommendations to an active } \\
\text { learner based on learning style and } \\
\text { learning sequence. }\end{array}$ & $\begin{array}{l}\text { AprioriAll } \\
\text { Collaborative } \\
\text { filtering }\end{array}$ & $\begin{array}{l}\text { Collabora } \\
\text { tive } \\
\text { filtering }\end{array}$ \\
\hline $\begin{array}{l}\text { Personalized } \\
\text { recommendation } \\
\text { of learning } \\
\text { material [6] }\end{array}$ & $\begin{array}{l}\text { Learning } \\
\text { objects }\end{array}$ & $\begin{array}{l}\text { Propose a new material } \\
\text { recommender system framework } \\
\text { and relevant recommendation } \\
\text { algorithms for } \\
\text { environments. }\end{array}$ & $\begin{array}{l}\text { Sequential pattern } \\
\text { mining } \\
\text { Apriori and } \\
\text { PrefixSpan } \\
\text { Nearest } \\
\text { neighborhood }\end{array}$ & Hybrid \\
\hline $\begin{array}{l}\text { Hybrid attribute } \\
\text { based } \\
\text { recommender } \\
\text { system for } \\
\text { learning material } \\
\text { [13] }\end{array}$ & $\begin{array}{l}\text { Resourc } \\
\mathrm{e}\end{array}$ & $\begin{array}{l}\text { Propose a hybrid recommender } \\
\text { system for learning materials } \\
\text { based on their attributes to } \\
\text { improve the accuracy and quality } \\
\text { of recommendation. }\end{array}$ & $\begin{array}{l}\text { Nearest } \\
\text { neighborhood } \\
\text { Preference } \\
\text { matrix } \\
\text { Genetic } \\
\text { Algorithm }\end{array}$ & Hybrid \\
\hline DELPHOS [14] & $\begin{array}{l}\text { Learning } \\
\text { objects }\end{array}$ & $\begin{array}{l}\text { Assist users in the search for } \\
\text { learning objects in repositories } \\
\text { and which shows an example of } \\
\text { application in engineering }\end{array}$ & Unknown & Hybrid \\
\hline $\begin{array}{l}\text { A hybrid system of } \\
\text { pedagogical } \\
\text { pattern } \\
\text { recommendations } \\
{[12]}\end{array}$ & Unknown & $\begin{array}{l}\text { Present a system that allows } \\
\text { lecturers to define their best } \\
\text { teaching strategies for use in the } \\
\text { context of a specific class. }\end{array}$ & $\begin{array}{l}\text { Singular value } \\
\text { decomposition } \\
\text { Nearest } \\
\text { neighborhood }\end{array}$ & Hybrid \\
\hline $\begin{array}{l}\text { Application of } \\
\text { implicit and } \\
\text { explicit attribute } \\
\text { for learning } \\
\text { resource } \\
\text { recommendation } \\
\text { [16] }\end{array}$ & Resource & $\begin{array}{l}\text { Propose a new resource } \\
\text { recommender system framework } \\
\text { for e-learning based on implicit } \\
\text { and explicit collaborative filtering } \\
\text { and sequential. }\end{array}$ & $\begin{array}{l}\text { k-means } \\
\text { Bi-Directional } \\
\text { Extension based } \\
\text { frequent closed } \\
\text { sequence mining }\end{array}$ & $\begin{array}{l}\text { Collabora } \\
\text { tive } \\
\text { filtering }\end{array}$ \\
\hline U-Learn [4] & $\begin{array}{l}\text { Learning } \\
\text { objects }\end{array}$ & $\begin{array}{l}\text { Help learners to accomplish their } \\
\text { goals, offers suggestions of } \\
\text { educational bibliographic } \\
\text { materials and tools through a } \\
\text { recommender agent based on } \\
\text { learning style. }\end{array}$ & Unknown & $\begin{array}{l}\text { Collabora } \\
\text { tive } \\
\text { filtering }\end{array}$ \\
\hline
\end{tabular}




\section{Architecture of Educational Recommender Systems}

In this section, we present a generic architecture for developing educational recommender systems. The architecture has a layered design in order to organize its components. This layered design allows scalability and easy maintenance because its tasks and responsibilities are distributed. The architecture of educational recommender systems is shown in Fig. 1. Each layer has a function explained as follows:

Presentation layer: This layer shows the end-user interface, allowing communication between the user and the systems. This layer is implemented by using HTML5, Java Script, and Cascading Style Sheets Level 3 (CSS3) for presenting information and allowing users to interact easily with the educational recommender systems.

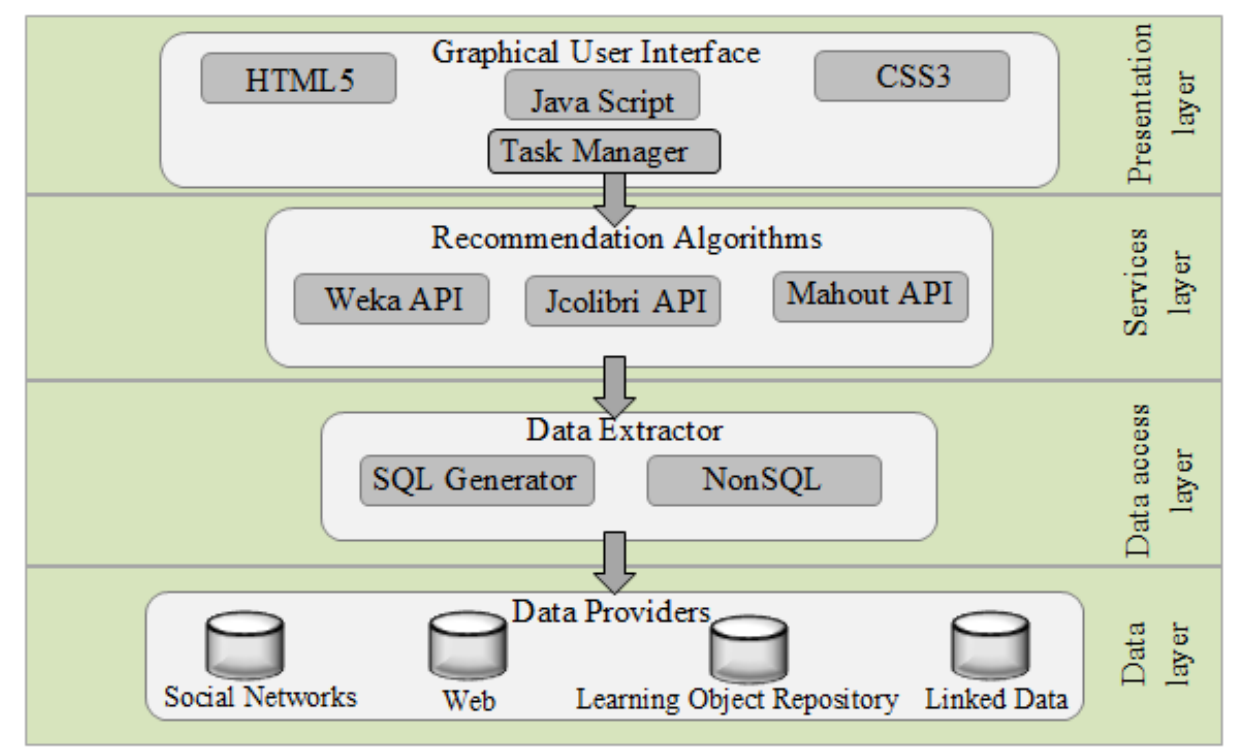

Fig. Educational Recommender Systems Architecture.

Services layer: This layer provides a set of APIs such as: 1) Weka which is a collection of machine learning algorithms for data mining tasks, 2) JColibri it is a java framework for building Case-based Reasoning (CBR) systems, and 3) Mahout API it is a library useful to build an environment for quickly creating scalable performant machine learning applications. These allow the generation of recommendations of educational resources. This layer has the recommendation algorithm that contains the metrics and algorithms for the generation of recommendations. The selection of the similarity metric is based over an analysis of several available metrics that are useful according to the data type.

Data access layer: A data extractor is located in this layer which maintains the data persistence, this layer is responsible of the proper execution of tasks such as insert, update, delete and query operations within educational recommender system's 
architecture. These tasks are encapsulated in this layer in order to provide security to the upper layers and avoid shortcuts on the data extractor.

Data layer: This layer stores information about the metadata educational resource provided by the educational recommender systems (video, books, and images, among others). Moreover this Data layer contains the different sources of information where educational resources may be located. As sources of information about educational resources for an educational recommender system, we can consider Social Networks as YouTube for video playing; SlideShare and Scribd to download slideshows, Picasa to visualize images. Other sources of information can be Learning Object Repositories. Some examples of these repositories are: MERLOT (Multimedia Educational Resource for Learning and Online Teaching), CAREO (Campus Alberta Repository of Educational Objects), SMETE (Science, Mathematics, Engineering and Technology Education) and others. At last, Linked Data can be considered where DBpedia is the main source of information for educational resources.

In this architecture, each component has a function which is explained as follows:

Graphical User Interface Component: This component represents the Graphical User Interface (GUI) which is responsible of handling the interaction between the user and recommender system. It is also a manager that captures user events, handles the task of validating all input data of the user. This component is responsible of handling user requests using the HTTP-based protocol.

Recommendation Algorithms Component: This component is responsible for the configuration of the algorithm implemented in the generated system. This component employs the WEKA API, JColibry API and Mahout API; it also includes several metrics for the calculation of similarity such as Pearson correlation, cosine measure and Euclidean distance.

Data extractor component: This component is responsible of retrieving all the information necessary for generating recommendation systems and its databases using SQL and NonSQL queries; therefore this component contains the SQL and NonSQL generator component, which allows generating the necessary SQL and NonSQL statements in order to create the system's persistence mechanism.

Data provider component: This component is responsible of providing persistence mechanism information required by the data extractor component. This information is located in Learning Object Repository, Social Networks, Web, Linked data.

\section{$4 \quad$ Main features of Educational Recommender Systems}

There are five main issues a recommender system must address. Firstly, a knowledge acquisition technique must be employed to gather information about the user from which a profile can be constructed. This knowledge is processed to provide the basis for an individual's user profile; it must thus be represented in a convenient way. There must be a knowledge source from which items can be recommended. Recommender systems allow information to be shared amongst users to enhance the overall recommendation performance; this shared information must be clearly defined. The final requirement is for an appropriate recommendation technique to be employed, allowing recommendations to be formulated for each of the users of the system. 
Domain knowledge can also be shared, since it is normally programmed in and hence available to the system from the start. Categorizations of items can be used to provide order to a domain, and common sets of domain heuristics, potentially part of a knowledge base, can be useful when computing recommendations.

Table 2. Main features of educational recommender systems.

\begin{tabular}{|c|c|}
\hline Feature & Description \\
\hline $\begin{array}{l}\text { Monitoring } \\
\text { behaviour }\end{array}$ & $\begin{array}{l}\text { An educational recommender system can observe the behavior of users based on } \\
\text { their interaction with the system The system records this behavior to track student } \\
\text { learning purposes instructional decision making and provide information to users } \\
\text { on their progress. }\end{array}$ \\
\hline $\begin{array}{l}\text { Heuristics to infer } \\
\text { information }\end{array}$ & $\begin{array}{l}\text { An educational recommender system uses a set of rules that are used to infer } \\
\text { information about users based on common preferences for decision making and } \\
\text { finding information. }\end{array}$ \\
\hline User feedback & $\begin{array}{l}\text { An educational recommender system uses the process of user feedback to provide } \\
\text { explicit information and thus confirm, add, overwrite, restructure information such } \\
\text { as domain knowledge. }\end{array}$ \\
\hline Filter rules & $\begin{array}{l}\text { Recommender system provides filtering rules to users in search of accurate } \\
\text { information that is related in the context of their learning. }\end{array}$ \\
\hline $\begin{array}{l}\text { User-created } \\
\text { groups/categories }\end{array}$ & $\begin{array}{l}\text { An educational recommender system allows users to define groups or categories in } \\
\text { order to group users with learning styles and common characteristics (age, sex, skin } \\
\text { color, socio-demographic characteristics among others) in the process of teaching } \\
\text { and learning. }\end{array}$ \\
\hline Item feedback & $\begin{array}{l}\text { Item feedback is used by a recommender system to help users in making decisions } \\
\text { for the selection of educational resources in the process of teaching and learning. } \\
\text { These educational resources have been rated by other users. The user decides what, } \\
\text { when, where, and what you want to study educational resources based on a feedback } \\
\text { process. }\end{array}$ \\
\hline Examples of items & Recommender system displays examples of items to form a collective training set. \\
\hline $\begin{array}{l}\text { Navigation } \\
\text { history }\end{array}$ & $\begin{array}{l}\text { A recommender system uses recorded navigation histories to help other users to find } \\
\text { an optimal route. }\end{array}$ \\
\hline Navigation trails & $\begin{array}{l}\text { A recommender system has a navigation history that identifies the plan or path that } \\
\text { a user continues in the learning process, such as a theme, a competition or a learning } \\
\text { objective; and so recommend ways and shortcuts to educational resources. }\end{array}$ \\
\hline $\begin{array}{l}\text { Crawled web } \\
\text { pages }\end{array}$ & $\begin{array}{l}\text { An educational recommender system tracks Web pages to make this information as } \\
\text { an ordered set of applications of pages visited by users. On this basis, browsing } \\
\text { sessions are inferred in order to optimize and evaluate the recommendation of } \\
\text { resources as well as propose alternative resources to users who share similar } \\
\text { characteristics. }\end{array}$ \\
\hline $\begin{array}{l}\text { Internal database } \\
\text { of items }\end{array}$ & $\begin{array}{l}\text { An educational recommender system contains an internal database of items to } \\
\text { generate the process of recommendation. }\end{array}$ \\
\hline $\begin{array}{l}\text { Similarity } \\
\text { matching }\end{array}$ & Similarity function is used to find items matching a content-based profile. \\
\hline $\begin{array}{l}\text { Collaborative } \\
\text { filtering }\end{array}$ & $\begin{array}{l}\text { An educational recommender system uses the technique of similarity as a statistical } \\
\text { function to find people with similar profiles, and then items liked by those people } \\
\text { are recommended. }\end{array}$ \\
\hline
\end{tabular}

Profiles can be represented as a feature vector in a vector-space model. This is a standard representation and allows easy application of machine-learning techniques when formulating recommendations. For content-based recommendation the features in the vectors might be the word frequencies of interesting documents, while for collaborative filtering the features could be the keywords commonly used by users in their search queries. Navigation trails can be used to represent time-variant user 
behavior. If some initial knowledge engineering has been conducted there may also be knowledge about the users available to a profile.

The domain itself will contain sources of information to be recommended to the users. These could be from a database held by the recommender system, such as movie titles, or available dynamically via the web, such as links from the currently browsed page or web pages crawled from a web site. Systems can also rely on external events, such as incoming emails, to provide items for recommendation.

There is a wide variety of recommendation techniques employed today, with most techniques falling into three broad categories. Rule filters apply heuristics to rank items in order of potential interest. Machine-learning techniques employ similarity matching to rank items in order of interest. Collaborative filtering finds similar users and recommends items they have seen and liked before.

After analyzing about 60 papers related to develop recommender systems, we have identified the main features of a recommender system under an educational context. Table 2 describes these main features.

\section{$5 \quad$ Conclusions and Future Work}

In educational process, a recommendation system provides many benefits such as reducing the time spent searching for educational resources that meet the needs, preferences and objectives of a student. An educational recommender system incorporates different levels of customization to the user in order to formulate a query that will reflect what are his/her short- and long-term, that is, what he/she wants to learn in one session or future sessions of learning through an extraction process his/her profiles. For these reasons educational recommender systems are a perfect tool that provides personalized support to each student in their learning process. We have presented a literature review about educational recommender systems and we have designed (which has not been tested yet) a generic architecture for developing educational recommender systems. Also, we have identified the main features that an educational recommender system must have.

As future directions, we are considering developing the modules identified in the architecture to build an educational recommender system that meets characteristics presented in this paper. Also we are considering to include opinion mining, sentimental analysis and building user profiles to generate recommendations of educational resources for further customization and minimize problems locating educational resources scattered in different repositories.

Acknowledgments. This work was sponsored by the National Council of Science and Technology (CONACYT), the National Technology of Mexico (TecNM) and the Public Education Secretary (SEP) through PROMEP.

\section{References}

1. Ricci, F., Rokach, L., Shapira, B.: Introduction to recommender systems handbook. In: F. Ricci, L. Rokach, B. Shapira, P. B. Kantor (eds.), Recommender systems handbook, pp. 135, Springer (2011) 
2. Luis Omar Colombo Mendoza, Rafael Valencia García, Alejandro Rodríguez González, Giner Alor Hernández, José Javier Samper Zapater: RecomMetz: A context-aware knowledge-based mobile recommender system for movie showtimes. Expert Systems with Applications, 1202-1222 (2015)

3. Aleksandra Klasnja Milicevic, Boban Vesin, Mirjana Ivanovic, Zoran Budimac: E-Learning personalization based on hybrid recommendation strategy and learning style identification. Computers \& Education, 56, 885-899 (2011)

4. Maria Iuliana Dascalu, Constanta Nicoleta Bodea, Alin Moldoveanu, Anca Mohora, Miltiadis Lytras, Patricia Ordoñez de Pablos: A recommender agent based on learning styles for better virtual collaborative learning experiences. Computers in Human Behavior, 243$253(2015)$

5. Maria Soledad Pera, Nicole Condie, Yiu-Kai Ng: Personalized Book Recommendations Created by Using Social Media Data. In: WISE 2010 Workshops, 6724, pp. 390-403 (2011)

6. Salehi Mojtaba, Isa Nakhai Kamalabadi, Mohammad Bagher Ghaznavi Ghoushchi. Personalized recommendation of learning material using sequential pattern mining and attribute based collaborative filtering. Educ Inf Technol (2012)

7. Mei Hua Hsu: A personalized English learning recommender system for ESL students. Expert Systems with Applications, 34, 683-688 (2008)

8. Hsua Chia Cheng, Chena Hsin Chin, Huangb Kuo Kuang, Huang Yueh Min: A personalized auxiliary material recommendation system based on learning style on Facebook applying an artificial bee colony algorithm. Computers and Mathematics with Applications, 64, 15061513 (2012)

9. Rosaci Domenico, Sarn Giuseppe M.L.: Efficient personalization of e-learning activities using a multi-device decentralized recommender system. Computational Intelligence, 26, 121-141 (2010)

10. Koutheaïr Khribi Mohamed, Jemni Mohamed, Nasraoui Olfa: Automatic Recommendations for E-Learning Personalization Based on Web Usage Mining Techniques and Information Retrieval. Educational Technology \& Society, 30-42 (2009)

11. Cristóbal Romero, Sebastián Ventura, Jose Antonio Delgado, De Bra Paul: Personalized Links Recommendation Based on Data Mining in Adaptive Educational Hypermedia Systems. LNCS 4753, pp. 292-306 (2007)

12. Carlos Cobos, Orlando Rodriguez, Jarvein Rivera, et al.: A hybrid system of pedagogical pattern recommendations based on singular value decomposition and variable data attributes. Information Processing and Management, 607-625 (2013)

13. Salehi Mojtaba, Pourzaferani Mohammad, Amir Razavi Seyed: Hybrid attribute-based recommender system for learning material using genetic algorithm and a multidimensional information model. Egyptian Informatics Journal, 67-68 (2012)

14. Zapata, A., V.H. Menéndez, M.E. Prieto, C. Romero: A framework for recommendation in learning object repositories: An example of application in civil engineering. Advances in Engineering Software, 1-14 (2013)

15. Holenko Dlab, Martina, Natasa Hoic-Bozic: Recommender System for Web 2.0 Supported eLearning. In: IEEE Global Engineering Education Conference (EDUCON), pp. 953-956 (2014)

16. Salehi Mojtaba: Application of implicit and explicit attribute based collaborative filtering and BIDE for learning resource recommendation. Data \& Knowledge Engineering, 87, 130$145(2013)$ 